\title{
El uso y abuso de Marcas
}

Por Blanca Ruth Orantes
Investigadora y Docente
Derecho Internacional

La propiedad intelectual se clasifica en: Derechos de Autor y Derechos Conexos, y Derechos de Propiedad Industrial, éste último comprende: marcas, nombres comerciales, expresiones o señales de publicidad comercial, emblemas, patentes de invención, modelos de utilidad y diseños industriales ${ }^{1}$.

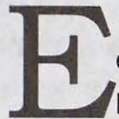

s un tema de interés, debido a que el uso y abuso de los derechos de propiedad industrial, específicamente el de marcas puede favorecer o afectar a propietarios y consumidores de las mismas, en el caso de éstos últimos la preferencia en marcas descansa en la confianza por su calidad, duración, etc.

En realidad el tema desencadena una diversidad de fenómenos, pero me referiré exactamente a dos aspectos que tienen que ver directamente con el uso y abuso de marcas: el régimen de competencia desleal y el interés de los consumidores como bien a proteger. De esa manera se presentan por separado y al final se hace un breve análisis al respecto.

\section{Régimen de competencia desleal.}

"La competencia desleal puede vincularse a los actos ilícitos que se dan en materia de Derechos de Autor como en lo que se refiere a la Propiedad Industrial" ${ }^{2}$, dicho fenómeno ha cobrado cada vez mayor importancia, logrando alcanzar un primer plano como punto importante en materia de tratados internacionales, buscando con ello establecer las condiciones de legalidad que los paises requieren para garantizar la inversión extranjera y la nacional. Siendo estas condiciones la principal condicionante para las negociaciones internacionales entre los paises industrializados y los países en vías de desarrollo.

Sin embargo juntamente con el desarrollo de este comercio, se dan fenómenos que no solo lesionan los derechos de propiedad industrial, especificamente a las marcas, sino también ponen en riesgo los derechos de los consumidores.

La población en general se puede ver afectada por la actividad del uso indebido en cuanto a la falsificación e imitación de productos de marcas. Como conøumidores estamos expuestos a ser defraudados en el mercado al adquirir un producto falso o una imitación con apariencia de genuino, lo que afecta nuestro bolsillo. Por ejemplo no estamos exentos de poner en peligro nuestra salud o la salud de los nuestros, al adquirir "medicamentos" pirateados; o en otros casos marcas que pueden confundirse, como es el caso de la marca de ropa interior femenina con gran prestigio "Lovable" y otra que es de menor calidad denominada "Lovabra", que usan similitud en colores, nombre y distintivo y que es común verlas en el mercado salvadoreño. 
pp. $4-10$

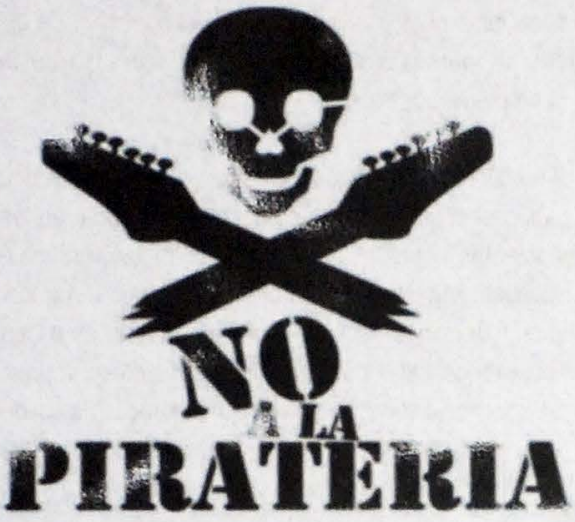

En los ámbitos del Derecho de la Propiedad Industrial, así como en el de Competencia Desleal, se utilizan una pluralidad de términos para referirse al fenómeno en mención, tal es el caso de la pirateria, imitación y falsificación, conocidos como ilícitos de la propiedad industrial. Sin embargo por competencia desleal habrá de entenderse aquel "obrar deliberado del ser humano cuya sola finalidad es el incremento de su industria o comercio, logrado por medio de una conducta deshonesta que perjudica a la industria o comercio del competidor"3.

Es un obrar deliberado, pues no puede entenderse que quien lo ejecuta lo haga con ignorancia, descuido 0 error. Además, se constituye siempre sobre el competidor, esto es, dirigiéndose hacia él, y produce una serie de efectos que van a perjudicarlo. La finalidad de este obrar deliberado es siempre la obtención de un provecho económico, que se logra a través de actuaciones contrarias a las reglas de la sana y libre competencia, o lo que es igual, contrarias a la moral y deberes del comerciante, a las costumbres comerciales del momento en que se producen.

Ese obrar deliberado ocasionará necesariamente serios perjuicios al competidor contra quien se dirige, que se manifestarán, ya en la disminución de su clientela, en el desprestigio de su nombre $o$ de sus productos.

Para prevenir y combatir estos ilícitos, existen sanciones de carácter penal, que van desde la prisión y multas, así como sanciones accesorias de carácter civil, que implica la destrucción, secuestro de ejemplares ilícitos, asimismo como elementos usados para su fabricación.

Para el caso de la pirateria, el autor Fremiort Ortíz toma el concepto de piratería del glosario de Derecho de Autor y Derechos Conexos publicado por la Organización Mundial de la Propiedad Intelectual (OMPI), que incorpora esta terminología, como una "figura juridica que atenta contra el Derecho de Autor, un material grabado (disco, casete) o impresos (libros, escritos, publicaciones periódicas) y vender encubiertamente- dicho material|"4 ; por el contrario Delia Lipszyc, especialista en esta rama del derecho, considera que "la piratería de obras y productos culturales, es la conducta antijurídica típica contra el derecho exclusivo de reproducción" ${ }^{5}$.

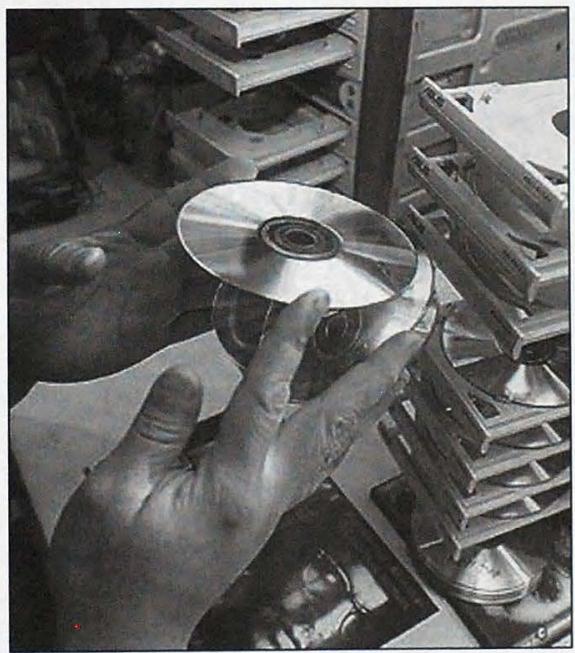

${ }^{3}$ BIBLIOTHECA MILLENNIO. Colección de Derecho Económico y de los Negocios. "Derecho de la Competencia". El Navegante Editores. Bogotá-Colombia, 1998. ${ }^{4}$ ORTIZ PIERPAOLI, Fremiort. "Derechos de Autor y Derechos Conexos". Primera Edición. Imprenta Salesiana. Asunción-Paraguay. 1998 p-234

"LIPSZYC, Delia. "Derecho de autor y derechos conexos". Ediciones UNESCO. CERLALC. ZAVALIA, Buenos Aires. 2001. p-559 
En ambos conceptos puede notarse una situación común, que la piratería es el atentado más común que afecta al Derecho de Reproducción, por cuanto es la acción de reproducir obras intelectuales, por cualquier medio conocido o por conocer, con el fin de ser distribuidas al público, sin autorización del autor.

Se está ante la tipificación de la pirateria como una figura jurídica y una distancia de antijurídica. Sin embargo puede observarse que el hecho de que se tipifique la piratería como una figura jurídica, no es que el derecho la regula, sino más bien debe ser tema de discusión entre los diferentes foros $y$ reuniones, en el sentido de establecer las medidas $y$ sanciones para combatir esta práctica que se ha vuelto cada vez mayor, por tal razón la legislación la tipifica dentro de lo que se conoce como competencia desleal.

Analizando lo antes expuesto, el perjuicio no sólo lo sufren el autor, sino también el editor (en la obra gráfica) los intérpretes y los productores de fonogramas, en las obras musicales. De allí que la pirateria también conlleve al delito de falsificación de marcas. Según ADPIC-TRIPS 6 la piratería se aplica más en materia de Derechos de Autor y Derechos Conexos, que para el caso de las marcas.

El más complejo de todos es el mal llamado Derecho de la Competencia Desleal, lo constituye "la imitación", ésta no es más que el aprovechamiento del esfuerzo ajeno y de la reputación ajena.

Como punto de referencia se presenta un concepto simple, pero que explica esta complejidad "imitación significa ejecutar una cosa a ejemplo o semejanza de otra" ${ }^{\prime \prime}$. Es decir no coincide exactamente con el que tiene los atributos reconocidos en el Derecho, de allí que la imitación esté contemplada dentro de la competencia desleal.

Para describir la expresión imitación se requiere de una explicación casi infinita: es decir puede darse en las siguientes figuras: marcas denominativas, gráficas, envases, envoltorios, nombres comerciales, rótulos, denominaciones sociales, colones, titulos, anuncios publicitarios, catálogos, máquinas industriales, objetos de adorno, diseños de todo tipo, aspecto físico de personajes famosos, uniformes de empleados, recetas de cocina, productos financieros, servicios de hosteleria, presentación exterior de los establecimientos, hasta estrategias de marketing.

Existe una clasificación de la imitación que implica varios tipos según Rangel Medina ${ }^{8}$, de los cuales se presentan a continuación, los más conocidos:

Imitación por reproducción: Cuando se copia el modelo a través de procedimientos como el calco, el vaciado, la fotocopia, el lápiz óptico, el scanner, cuyo resultado es la obtención de una presentación idéntica al modelo.

Imitación conceptual: Se lleva a cabo a través de la traducción de una denominación que se expresa en otra lengua o lenguaje (gráfico, simbólico).

Imitación por contraste: Cuando la contradicción opera como desencadenante de la unión mental.

Imitación por complementariedad: Utilización de una expresión o de una idea que forma parte del conjunto del que se ha extraido el modelo.

\footnotetext{
${ }^{6}$ Acuerdo sobre los Aspectos de los Derechos de Propiedad Intelectual relacionados con el Comercio (ADPIC/TRIPS) ratificado por El Salvador. ${ }^{7}$ Diccionario de la Real Academia Española, 21.a. ED., p-1143

"RANGEL MEDINA, David. "Tratado de Derecho Marcario". Las marcas industriales y comerciales en México. s/r D.F. 1960.
} 
En materia de derecho comparado, tanto el Convenio de París, como el Acuerdo sobre los Aspectos de los Derechos de Propiedad Intelectual Relacionados con el Comercio (ADPIC/TRIPS), asi el Convenio de Berna para la Protección de Obras Literarias y Artísticas, la Convención de Roma para la Protección de los Artistas, Intérpretes, Ejecutantes, Productores de Fonogramas y Organismos de Radiodifusión, la Convención Universal sobre Derecho de Autor, el Tratado de la Organización Mundial de la Propiedad Intelectual OMPI sobre Derecho de Autor (WCT) y el Tratado de la Organización Mundial de la Propiedad Intelectual OMPI sobre Interpretación o Ejecución y Fonogramas (WPPT); igual la legislación Salvadoreña especial, tipifican la imitación no de una forma expresa, la tienen comprendida dentro de la competencia desleal.

Para una mejor ilustración conceptual de las diversas formas de competencia desleal, se presenta el siguiente cuadro:

\begin{tabular}{|c|c|c|}
\hline PIRATERIA & IMITACION & FALSIFICACION \\
\hline $\begin{array}{l}\text { - Acción de reproducir obras } \\
\text { intelectuales, ya sea ésta } \\
\text { reedición. } \\
\text { - Fabricación y/o venta de } \\
\text { ejemplares ilegales (sean obras } \\
\text { literarias, artísticas, } \\
\text { audiovisuales, musicales), } \\
\text { incluyen. } \\
\text { - No reúne las condiciones de } \\
\text { originalidad. }\end{array}$ & $\begin{array}{l}\text { - Semejanza con otra, pero } \\
\text { que no es igual, puede tomar } \\
\text { solamente algunos elementos } \\
\text { de la original y valerse del } \\
\text { prestigio de } \\
\text { ésta última. } \\
\text { - No reúne las condiciones } \\
\text { de originalidad. }\end{array}$ & $\begin{array}{l}\text { - Es la falsificación total, es } \\
\text { decir, aprovechando la } \\
\text { tecnología avanzada, se } \\
\text { aprovechan del trabajo de otro } \\
\text { usurpando los derechos de } \\
\text { éste. } \\
\text { - No reúne las condiciones de } \\
\text { originalidad. }\end{array}$ \\
\hline
\end{tabular}

El punto común es que en ningún caso ni la piratería, ni la imitación y la falsificación reúnen las condiciones de originalidad. Y esto es grave para el caso de nuestro pais, en donde es común encontrar productos y marcas bajo estas figuras ilicitas.

El problema es mayor, cuando existen múltiples compromisos, como los contraidos en Tratados de Libre Comercio, en donde las exigencias son mayores por parte de los inversionistas que exigen un marco jurídico confiable. $Y$ que decir de los consumidores, que deben contar con un marco jurídico garante de sus derechos. En ambos casos el Estado tiene

Entorno ISSN: 2218-3345 un compromiso ineludible y urgente de resguardar y tutelar estos derechos.

En el siguiente apartado se aborda el interés de los consumidores vinculado a la competencia desleal, especificamente en lo que se refiere a marcas.

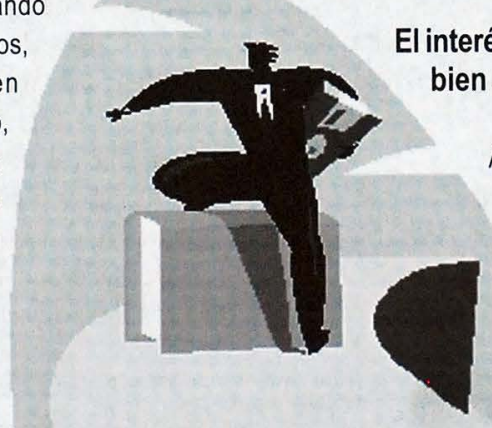


posturas más garantistas de los demás intereses implicados, confiando la protección mediata a éstos a la actuación de aquellos, ese interés privativo a proteger se ve todavía reforzado cuando se trata de marcas notorias o renombradas.

Durante los últimos años se ha seguido una línea de fortalecimiento de estos derechos y en particular del derecho de marcas, es decir se ha dado un reconocimiento internacional, firmando Tratados, como los mencionados en el apartado anterior, que obligan a los Estados a dar una protección más efectiva, es decir resalta en esta tendencia el valor económico de la marca, debido a su importancia en el mercado, el cual exige que los Estados establezcan un sistema de competencia no falseada, es decir que se combata la competencia desleal. ${ }^{9}$

El derecho de marca es un derecho sobre un bien inmaterial, que perteneciendo a su titular registral desempeña un papel relevante en la regulación y transparencia del mercado. Desde esta perspectiva, constituye también un mecanismo relevante para la tutela y protección de los consumidores. No debe olvidarse que la marca cumple un conjunto de funciones en el sistema jurídico, dentro de estas funciones se encuentra la de indicar la procedencia empresarial de los productos o servicios designados con la marca y la función de indicar al consumidor la calidad de dichos productos o servicios. La marca permite asi un correcto funcionamiento del sistema de libre competencia y hace posible que los consumidores obtengan información fidedigna sobre el origen y la calidad de los productos o servicios.

Estas consideraciones fueron tomadas en consideración tanto por los sistemas internacionales como los nacionales en cuanto a la protección legal, por ello para el caso del derecho de consumidores y dar cumplimiento al mandato constitucional, establecido en el artículo 101 inciso $2^{\circ}$. de la Constitución, EI Salvador aprobó la Ley de Protección al Consumidor el 4 de noviembre de $1996^{10}$, estableciendo la Dirección General de Protección al Consumidor para los procedimientos administrativos. Además cuenta con el Código de Ética Publicitaria de El Salvador que regula la publicidad en lo que se refiere a tratamientos y productos médicos y algunas disposiciones legales en el Código Penal para sancionar la competencia desleal.

En síntesis, sólo tutelando la marca y el interés de su titular, sólo evitando que un tercero intente aprovecharse del prestigio o fama ajenos usando en el mercado signos confundibles con los de titulares registrales anteriores, se podrá lograr que la marca cumpla su función en el mercado y que el interés de los consumidores se encuentre debidamente amparado.

Al posibilitarse que en un mismo mercado aparezcan productos dotados con el mismo signo para "identificar" productos con diferente origen empresarial| ${ }^{11} \mathrm{y}$ con una calidad también diferente, se estaria permitiendo un triple perjuicio:

1) perjuicio directo a los intereses económicos y empresariales del titular de la marca original;

2) perjuicio a los consumidores medios al fomentarse el riesgo de error sobre el origen y la calidad de los productos o servicios; $y$

3) perjuicio irreparable a la marca como mecanismo jurídico esencial en el sistema de competencia.

Entonces, si la marca no puede realizar su función esencial de indicar el origen empresarial del producto y del servicio que distingue, pierde toda su razón de ser, provocando a la vez la desnaturalización del sistema de libre mercado. Es decir para que la marca

\footnotetext{
${ }^{9}$ MONTIANO MONTEAGUDO. "El riesgo de confusión en derecho de marcas y en derecho contra la competencia desleal", ADI, XV. 83,1993 . p-117

${ }^{10}$ Publicado en el Diario Oficial No. 209 Tomo 333 del 6 de noviembre de 1996. El Salvador, Centroamérica.

"La función de origen del producto como la función esencial del derecho de marca reconoce la necesidad de proteger otros intereses como el interés del titular de la marca de que no se degrade la reputación de la marca o en el caso de determinados productos su "aura de lujo". Tribunal de Justicia de España. Sentencia 4 de noviembre de 1997. fundamento juridico 43 Perfums Christian Dior, S.A. Y Perfunms Cristian Dior BV c. Evora BV Tomado de CASADO CERVIÑO, Alberto Opus cit. pp-74-77.
} 


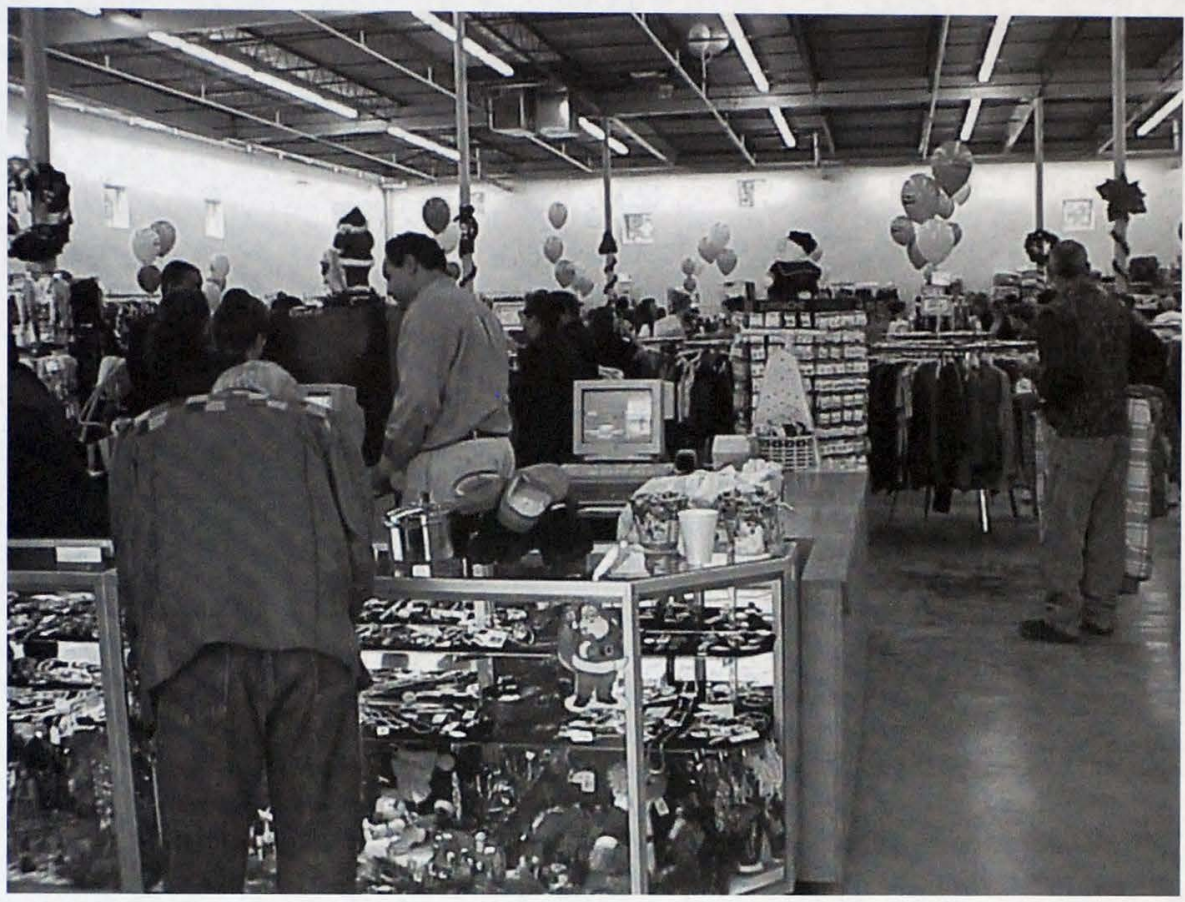

pueda cumplir sus funciones, es necesario que la misma sea protegida por un derecho exclusivo.

El interés del público de los consumidores se consigue, tutelando los distintos intereses en juego. Protegiendo, por un lado, el derecho privativo del titular de la marca y permitiendo, por otro lado, que el signo pueda cumplir sus funciones en el mercado. Si el derecho de marca se debilita, si se permiten prácticas desleales que pueden afectar el goodwill ${ }^{12}$ de la marca, privándola de su contenido, no será posible que ese signo cumpla sus funciones en el mercado. En consecuencia, los consumidores no podrán prevalerse de uno de los instrumentos fundamentales para distinguir los productos y servicios entre sí y conocer su origen y su calidad.

\section{Conclusión}

Aproximándonos a la realidad actual, en El Salvador impera un régimen de competencia desleal bastante flexible, es decir, recorriendo el sector comercio, puede encontrarse desde $\mathrm{C} d$ de música y películas; medicinas y ropa, con evidente imitación, falsificados o pirateados, lo que indica la ineficacia de mecanismos juridicos y judiciales para erradicar este fenómeno que no es para nada saludable, pues en la medida que no se combata ninguno de los fenómenos expuestos en materia de propiedad intelectual en general y de marcas en particular, no puede garantizarse esos derechos a los propietarios de marcas, y en este mismo orden tutelar el interés de los consumidores, para que no seamos engañados y hasta poner en riesgo nuestra salud y vida.

\footnotetext{
${ }_{12}$ Goodwill: Significa el fondo de comercio, es un término contable y económico, definido como el conjunto de elementos intangibles o inmateriales de la empresa que impliquen valor para la misma. La forman entre otras: la clientela, la razón social, la ubicación de la empresa, que vienen siendo como ventajas comparativas. Tomado de la página electrónica de Es. Wkipedia.org/ 15 de enero de 2007.
} 


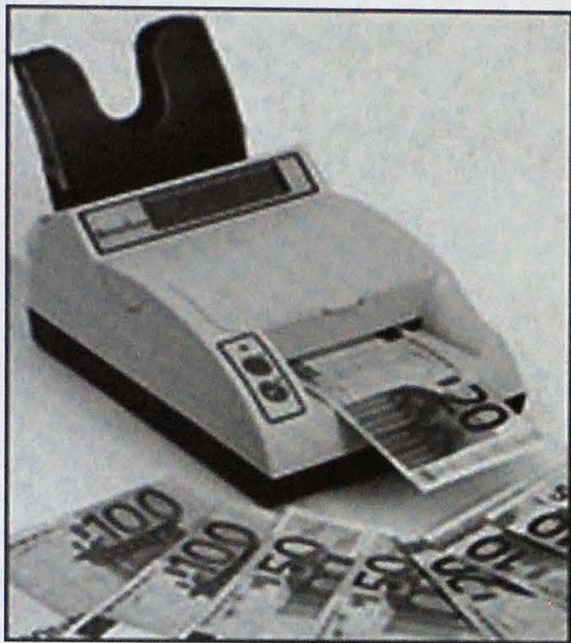

Fuentes de información

Fuentes Impresas

BARONA VILAR, Silvia. "Competencia Desleal". $2^{\mathrm{a}}$. Edición. Valencia, España 1999.

BIBLIOTHECA MILLENNIO. Colección de Derecho Económico y de los Negocios. "Derecho de la Competencia". El Navegante Editores. BogotáColombia, 1998.

CASADO CERVIÑO, Alberto. "Derecho de marcas y protección de los consumidores: el tratamiento del error del consumidor". Editorial TECNOS, Madrid, España, 2000.

CODIGO DE ETICA PUBLICITARIA DE EL SALVADOR. Consejo Nacional de la Publicidad. San Salvador, El Salvador, Centroamérica 1965.

CODIGO PENAL DE LA REPUBLICA DE EL SALVADOR.

CONSTITUCION DE LA REPUBLICA DE EL SALVADOR. Explicada. FESPAD ediciones. Sexta edición 2001. San Salvador, El Salvador, Centroamérica.

Diccionario de la Real Academia Española, 21.a.ed.

LEY DE PROTECCION AL CONSUMIDOR Y DISPOSICIONES COMPLEMENTARIAS. D.O. No. 209, Tomo 333 del 6 de noviembre de 1996. Editorial Jurídica Salvadoreña. El Salvador.

LIPSZYC, Delia. "Derecho de autor y derechos conexos". Ediciones UNESCO. CERLALC. ZAVALIA, Buenos Aires, 2001.

MONTANO MONTEAGUDO. "El riesgo de confusión en derecho de marcas y en derecho contra la competencia desleal", ADI, XV. 83, 1993.

ORTIZ PIERPAOLI, Fremiort. "Derechos de Autor y Derechos Conexos". Primera Edición. Imprenta Salesiana. Asunción-Paraguay. 1998.

OTAMENDI, Jorge. "Derecho de Marcas" Tercera edición ampliada y actualizada. Abeledo Perrot. Buenos Aires, Argentina. 1999.

PORTELLANO DIEZ, Pedro. "La imitación en el Derecho de la Competencia Desleal". EDITORIAL CIVITAS, S.A. Madrid, España, 1995.

TRATADOS INTERNACIONALES EN MATERIA DE PROPIEDAD INTELECTUAL. ASIPI. Asociación Interamericana de la Propiedad Industrial. Impreso en CICETRONIC OFFSET Quito - Ecuador. 1995.

RANGEL MEDINA, David. "Tratado de Derecho Marcario". Las Marcas Industriales y Comerciales en México. D.F. 1960.

\section{Fuentes electrónicas:}

Sitio Centro Nacional de Registro:

http://www.enr.gob.sv/ 